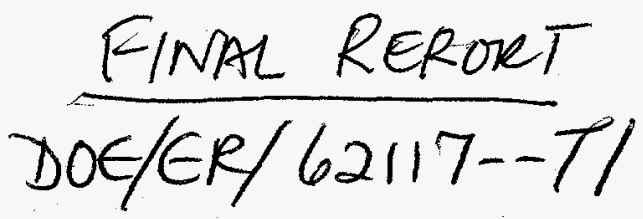

TECHNICAL REPORT for DOE Contract No. FG03-95ER62117

\title{
Summary of Accomplishments and Research on Forward-in-time Differencing for Shallow Fluid Flows on the Sphere
}

\author{
Piolr Smolarkiewicz, NCAR/MMM and Len Margolin, LANL
}

August 1, $: 997$

This past year we have comtimued the development of our 3D grid point model. The general model is nonhydrostatic, is written in noworthogonal terrain following coordinatess; and consistently incorporates either Eulerian or semi-Lagrangian differencing. The nonbydrostatic: formulation will be particularly use:ul when the grid size is small onough to resolve nomhydrostatic; processes-for exarnple: convective instabilities, and internal gravity wave dynamics in deep sheared atmospheres. However, we have also found that the nonhydrostatic formulation has numerical advantages on coarser grids, such as a better conditioning of the Laplacian matrix that must be inverted. In addition, use of the nonhydrostatic equations allows consistency as the mesh is refined, or when using nested grids.

We have used this model as a vehicle to compare the advantages of Eulerian and semiLagrangian incthods. At present, it appears that each method has advantages for certain classes of probleras, and that neither is uniformly superior. The nonhydrostatic model has additional options, including moving boundaries and treatment of moist precipitating processes.

We have incorporated more options into different versions of the basic model. The most significant step has been to move the semi-Lagrangian version of the model to the sphere, and to incorporate a hydrostatic option. In addition to providing an intexpertsive alternative for large scale simulations, the hydrostatic solution provides an excellent first guess for the nonhydrostatic: solution, thereby reducing the number of iteratious required to solve the 3D elliptic equations for prcsisure. We have also developed an effective preconditioner for this equation.

We have implemcnted a fairly sophisticated suhgrid scale turbulence parameherization in the basic model and performed a number of LES studies of planetary boundary layers to calibrate the model. Wo have ported the basic model to the Cray T3D using both a High Performance Fortran and a messige passing approach. We have conducted detailed comparisons of the model performance for various options of model algorithrus and concluded that the message passing approach offers uniformly superior performance for both serni-Lagrangian and Eulerian, and moist, and dry variants, of the model. We have also imsplemented a volume of thid (VOF) capability in the 20 model. VOF is an interface reconstruction method that approxirnates the motion of a Lagrangian interface on an Eulerian grid. For example, using VOF to represent the houndary of a cloud allows one to track the rnotion of the interface, keeping it sharp without using fine resolution. The cloud boundary is not exactly a Lagrangian surface because of the thermodynamic: processes of condensation and evaporation. 'These processes are stiff, and the compling of 


\section{DISCLAMMER}

This report was prepared as an account of work sponsored by an agency of the United States Government. Neither the United States Government nor any agency thereof, nor any of their employees, makes any warranty, express or implied, or assumes any legal liability or responsibility for the accuracy, completeness, or usefulness of any information, apparatus, product, or process disclosed, or represents that its use would not infringe privately owned rights. Reference berein to any specific commercial product, process, or service by trade name, trademark, manufacturer, or otherwise does not necessarily constitute or imply its endorsement, recommendation, or favoring by the United States Government or any agency thereof. The views and opinions of authors expressed herein do not necessarily state or reflect those of the United States Government or any agency thereof. 


\section{DISCLAIMER}

Portions of this document may be illegible electronic image products. Images are produced from the best available original document. 
the VOF tcchnique to thermodynanics requires some care.

In order to further improve the effeicns:y of our model, we have developed a new melihod for treating systems with a variety of tinc scales. Traditional strategies, induding split uxplicit methods, scmi-implicit methods, and mode splitting, all have some inaccuracies and/or stability jroblems. Our new nnettod, which we have named the rnetbod of averages (MOA), is based on three steps. In the first step, we find a low-order solution of the lincariyed equations on the fast timestep. In the second step, wo average these solutions over the slow timostep. In the third step, we use theso average solutions to do a single high-order solution of the full equations over the slow limbstep. The gain in efficiency connes about from solving only low-order linearizad equations on the fast timestep. In particular, the advection can be simple donor cell and oven an advective form of the equations can be used. To validate the method, we built a $2 \mathrm{D}$ shallow water model of an oecan basin. We used this model to simmlate a problem of a vortex interacting with a boundary. The vortex evolves on a slow time scale, while the interaction with the boundary results in Kelvin waves that evolve on a fast time scale. Using the MOA, we were able to reduce the standard small-time-step integration CP[] time by roughly 80efficiency factor is also predicted by our theory. Our results so far have served to validate the MOA; we bolieve: further gains in efficiency are possible by treating sorne terms on the slow scale (but not. the slow terms that are part of the principal balince).

Amuong others, we have written a review paper to help facilitate the transfor of the MPDATA technology that we have developed. The paper dcscribes the basic use of MPDATA for advection problems, and then progresses to applications of the full equations of molion. We also describe many options developed to improve the accuracy and efficiency of application.

\section{Publications:}

\section{a) refereed}

Nadiga, B.T., L.G. Margolin, and P.K. Smolarkiewicz, 1996: "Dispersive shallow fluid flow over a mounlain," Phys. of Fluids., 8, 2066-2077.

Smolarkiewicz, P.K., Grubisic:, V., and L.G. Margolin, 1996: "On forward-in-time differencing for fluids: Stopping criteria for iterative solutions of anelastic pressure equations," Mon. Wea. Kev., 125, 647-654.

Andersion, W.D., ind P.K. Smolarkiewicz, 1997: "A comparison of high performance Fortran and message pesssing parallelization of a geophysical fluid modol," in Parallel Computational Fluid Dynamics: Algorithms and Resulls Using Ad'ounced Computeris, Eds., P. Shiano, A. Ecer, J. Periaux, and N. Satofuka, Elsevier Science, 384391.

Anderson, W.D.: Grubisic, V., and P.K. Smolarkiewic:, 1997: "Performance of a massively parallel 3D non-hydrostatic atmospheric: flud modol" in Proceedings of the Interzutional Conference on Parallel and Distributed Processing Techniques and Applications, PDPTA'9\%, Las Vegas, Nevada, USA, June 30-July 3, Ed. IJ.R. Arabnia, CSRIBA, 